\title{
Hume, The Philosophy of Science and the Scientific Tradition
}

\author{
Matias Slavov
}

In Sager A., Coventry A. (eds), The Humean Mind, 388-402, Routledge.

At his own time, Hume was known primarily as a historian and essayist. He was not known as a natural philosopher or, to use our terminology, a natural scientist. ${ }^{1}$ Hume is usually not placed in the canonical listings of the history of early modern science, which include figures like Isaac Newton (1646-1727), Robert Boyle (1627-1691), Christiaan Huygens (1629-1695), and Carl von Linné (1707-1778).

Hume's contributions to "philosophy and general learning" revolve around his science of man and the study of the human mind. Even though he probably wanted to emulate the explanatory success of Newton's natural philosophy in his moral philosophy, the main concern of his philosophical work is in mapping the cognitive structures of the mind (Ott 2009: 191; Harris 2015: 85). Hume's objective is not to explain the "natural and physical causes" of our perceptions, as this task is for "the sciences of anatomy and natural philosophy" (T 2.1.1.2; SBN 275-6). Hume's ambition is to develop a human science which is different from natural science.

Although the main focus of Hume's career was in the humanities, his work also has an observable role in the historical development of natural sciences after his time. To show this, I shall center on the relation between Hume and two major figures in the history of the natural sciences: Charles Darwin (1809-1882) and Albert Einstein (1879-1955). Both of these scientists read Hume. They also found parts of Hume's work useful to their sciences. Inquiring into the relations between Hume and the two scientists shows that his philosophical 
positions had a partial, but constructive role in the formation of modern biology and physics. This is accordingly a clear indication of Hume's impact on the scientific tradition.

Before proceeding to analyze Hume's contribution to the history of science, it is important to address his broader role in the history of philosophy of science. Hume's discussions concerning the topics of causation, induction, the distinction between mathematical and empirical propositions, and laws of nature have been important for the philosophy of science of the nineteenth and twentieth centuries.

\section{Hume in the History of Philosophy of Science}

Among scholars who contributed to the philosophy of science in the eighteenth century, the background of Hume (as well as the British empiricist tradition more broadly conceived) can be seen in the influential work System of Logic by John Stuart Mill (1806-1873). Mill was sympathetic to Hume's account of causation and induction. Inhe alsosomewhat developed it. He thought, as Hume had argued, that there are no objective necessary connections among species of objects or events. Inductive inference does not guarantee apodictic certainty. However, this is not to deny inductive inference. It is possible to address different levels of probability to propositions concerning matters of fact (Wilson 2016: section 3, Induction).

In the twentieth century philosophy of science, Hume's impact can be seen most clearly in the doctrines of logical positivism. In Alexander Rosenberg's (1993: 64) estimation, the positivists and members of the Vienna Circle even preferred to call their program logical empiricism, to show their debt to Humean empiricism rather than to Auguste Comte's (17981857) positivism. 
A particularly good example of Hume's influence on logical positivism can be found in A.J. Ayer's (1910-1989) 1936 book Language, Truth and Logic. In retrospect, as a popularization of "what may be called the classical position of the Vienna Circle," Ayer characterized "Language, Truth and Logic as being no more than Hume in modern dress" (Ayer 1959: 8; 1987: 24). Right from the beginning of his work, Ayer endorses, in no uncertain terms, Hume's distinction between the propositions concerning relations of ideas and matters of fact. Thus he commences his work: "Like Hume, I divide all genuine propositions into two classes: those which, in his terminology, concern 'relations of ideas', and those which concern 'matters of fact." Within the former Ayer includes analytic "a priori propositions of logic and pure mathematics," and to the latter synthetic "propositions concerning empirical matters of fact." Ayer understood analytic propositions to be true in virtue of their meaning, and synthetic propositions to be "determined by the facts of experience." He took himself to be following Hume's footsteps, holding analytic statements to be necessary and certain, whereas empirical facts are "hypotheses, which can be probable but not certain" (Ayer 2001: 9, 72-3).

To produce textual evidence for his starting point, Ayer quotes the famous concluding paragraph of Hume's first Enquiry. In Ayer's (1959: 10) opinion, this paragraph is “an excellent statement of the positivist's position":

"When we run over libraries, persuaded of these principles, what havoc must we make? If we take in our hand any volume; of divinity or school metaphysics, for instance; let us ask, Does it contain any abstract reasoning concerning quantity or number? No. Does it contain any experimental reasoning 
concerning matter of fact and existence? No. Commit it then to the flames: For it can contain nothing but sophistry and illusion" (EHU 12.34; SBN 165).

In Ayer's view, Hume was the first hero of logical positivism. He thought that Hume championed the divide between the analytic and the synthetic. As the truths of mathematics and logic were to Ayer analytic and a priori necessary, he saw the movement of logical positivism to have vindicated "the empiricist claim that there can be no a priori knowledge of reality" (Ayer 2001: 83). If Ayer's Hume-interpretation were correct, he had a good reason in stating that "it is indeed remarkable how much of the doctrine that is now thought to be especially characteristic of logical positivism was already stated, or at least foreshadowed, by Hume" (Ayer 1959: 4). ${ }^{2}$

Although logical positivism was the most influential tradition in the philosophy of science between the two world wars, the movement eventually came to an end. In 1967, John Passmore (1967: 57) famously voiced that logical positivism "is dead, or as dead as a philosophical movement ever becomes." In its philosophy, there were a number of irresolvable problems. The principle of verifiability, according to which a cognitive statement is meaningful only if it is empirically testable, was self-refuting: the principle could not itself stand the test. Ludwig Wittgenstein's (1889-1951) later philosophy indicated the problems of radical concept empiricism. In his Philosophical Investigations, Wittgenstein argued that the meaning of the word is its use in a language game. The Humean-positivist theory had maintained that words get their meaning by a reference to sensuous impressions; this was now seen as a commitment to an untenable doctrine of private language. W.V. Quine (19082000) set forth a detailed critique of the analytic synthetic divide in his groundbreaking article "The Two Dogmas of Empiricism" (1951). He argued that the truths of pure 
mathematics and logic are not in principle distinguishable from the propositions of empirical science. In Quine's holism, the totality of our knowledge and beliefs form a sphere "which impinges on experience only along the edges" (Quine 1951: 39). Although logical and mathematical truths are in the center of the sphere, and most unlikely to be revised, they are still not immune from the findings of the empirical sciences. In the 1970's, a rehabilitation of metaphysics was seen in the philosophies of Saul Kripke, Hilary Putnam (1926-2016) and David Lewis. Their works recreated traditional metaphysical questions of essences, natural kinds and rigid designation (Ladyman \& Ross 2007: 9).

Karl Popper's (1902-1994) philosophy of science was essentially a reaction to the positivist verification principle. He viewed Hume's account of induction both positively and negatively. He thought that Hume had shown that there cannot be legitimate truth-preserving inductive inference. However, Popper (1972, section 1) also argued that science does not and should not employ induction. In his view, the proper logic of science is falsificationism based on the modus tollens rule of inference. Popper has been, however, criticized for "smuggling" induction in his notion of corroboration of theories. William Edward Morris (2011: 460) argues that

“corroboration isn't really much different from confirmation, and seems to have an inductive inference embedded in it - the inference from the fact that a conjecture has thus far escaped falsification to the (admittedly fallible) conclusion that it will continue to do so.

Since corroboration provides a way to accept conjectures $[\ldots]$, it is ampliative, and therefore should count as a non-demonstrative form of 
inference. To the extent that Popper's theory is inductive, it fails to evade Hume's argument."

The fact that Popper was not able to refute Hume on induction, does not mean that philosophers of science after him would subscribe to induction as the logic of science. Contemporary philosophers of science, for example, Peter Godfrey-Smith (2003: Chapter 3), have argued for pluralism of scientific inferences; there is no one valid mode of inference but several modes, including induction, deduction and abduction.

Hume's regularity theory of causation (which is the traditional interpretation of his position), ${ }^{3}$ has been reviewed critically by contemporary metaphysicians and philosophers of science. The basic problem of the regularity theory is that it does not properly distinguish between correlation and causation. To paraphrase Nancy Cartwright (1979), regularity is not sufficient for making a difference between effective and ineffective strategies. Buying a certain health insurance is statistically correlated with a longer lifetime, but the purchase of the insurance is not an effective strategy for prolonging one's life (as compared to physical exercise and proper diet). In addition to regularity, or probability of effects appearing after their causes, it has been suggested that causation needs also to be defined in counterfactual and interventionist terms. The counterfactual condition requires that if a cause did not happen, its effect would not ensue either (Menzies 2014). The interventionist position emphasizes the role of manipulability in causal relations: if the cause is intervened on, there will be a change in the effect (Woodward 2003).

In contemporary philosophy of physics, Hume's account of the metaphysics of laws of nature remains highly influential. It is commonplace to introduce two rival positions on the modal 
status of laws: the Humean and the non-Humean. According to the former position, laws are accurate records of universal generalizations. The non-Humean positions maintains that there is a specific modal character in laws of nature, namely physical necessity. Non-Humeanism about laws maintains that the Humean view is not able to make a credible distinction between laws and accidentally true generalizations. To explain the non-Humean view, consider the following claims. There are no golden or uranium spheres larger than one mile in diameter. Although both of these claims are true, the first is true by accident: it would be physically possible to construct such a golden sphere. But it would not be physically possible to construct such an uranium sphere; this is restricted by the laws of nuclear physics (Carroll 2016). The non-Humeans maintain that, for example, massy particles cannot travel at the speed of light, whereas the Humeans hold the more cautious view that so far we have not been able to produce such accelerations.

Hume's science of human nature is also relevant for contemporary neuroscience and philosophy of mind. This is evident in Antonio Damasio's work Descartes' Error (1995). In his work, Damasio (1995: 108) explicitly draws on Hume's notion of mental images, which can be both "faint" and "lively." There are many important parallels in their positions: the centrality of representational images in our thought, the quintessential role that emotions play in cognition, and the denial of substantial self in which our mental states supposedly inhere. As Morris (2011: 471) puts it, Damasio brings “many of Hume's fundamental views into an exciting, plausible, and - ultimately - testable account of human cognition."

In the next section, I shall draw my attention to Hume's role in the history of science by concentrating on his relation to two major figures of the scientific tradition: Darwin and Einstein. I shall argue that Darwin's reading of Hume strengthened his naturalistic world view 
which maintains that the difference between human and animal reason and cognition is a matter of degree, not kind. This contributed to Darwin's theory of evolution and natural selection. Both Hume and Darwin thought that reason is not a special human faculty, but that it evolves gradually from animal instincts. In the subsequent section, I shall argue that Einstein inherited from Hume (and Mach) an empiricist theory of concepts, which he then went on to realize in his argument for the relativity of simultaneity. This fundamental result of the special theory of relativity debunked the Newtonian assumption that time is absolute. Hume, and the empiricist tradition more broadly, paved the way for a critical understanding of the ontology of time (and space) as not being absolute, self-sustaining structures.

\section{Hume and Darwin: Reason, Cognition, and the Human-Animal Distinction}

To paint with a very broad brush, the dominant view in the history of Western philosophy regarding the relationship between humans and animals is anthropocentric. In ancient, medieval and early modern philosophy, many prominent philosophers assumed that there is a categorical difference between human and animal reason.

Since Plato (427-347 BC) and Aristotle (384-322 BC), and especially since neo-Platonism in late Antiquity, a very popular view concerning the relationship between the beings of the world was expressed in the idea of the ladder of nature (scala naturae) (Bunnin \& Yu 2004: 289; Lovejoy 1936: 58-59). According to this view-sometimes also referred to as the "Great Chain of Being" - there is a hierarchical structure in the world. This hierarchy includes the divine, living and non-living parts of the universe. In the highest category there is God. In the next category come divine creatures like angels. After this there are humans, next animals, and then plants. Inanimate matter is placed at the lowest level. 
In the scholastic period in Europe (roughly 1100-1500), theological considerations together with philosophical discussions based on the Aristotelian tradition emphasized the difference between human and animal reason. Thomas Aquinas shared the view of the ladder of nature. In his view, only humans and supreme beings like angels and God are intellectual. Human intellect is the lowest form of the intellect (Clark 2000: 66). Aquinas' conception is a direct continuation of the Aristotelian conception, which states that only humans have the rational part of the soul.

In the early modern period, Descartes' philosophy provides the clearest example of the view that there is a categorical difference between human and animal reason. In Descartes, only humans and angels are beings with minds. He thought that non-human animals are automata, sophisticated mechanical organs created by God. Descartes argues in his Discourse of the Method that reason is "the only thing that makes us men and distinguishes us from the beasts [lower non-human animals]." He did not think that "beasts have less reason than men," but that "they do not have reason at all" (Descartes 2000: 68, 148).

Hume's position regarding the distinction between human and animal reason is very different compared to the traditional view in the history of Western philosophy. This is evident both in his Treatise and his first Enquiry. On Hume's account, animal and human cognition works in fundamentally the same manner. This account concentrates on the notions of experience, causation, and uniformity of nature.

For Hume, we receive information of causal relations by experience (T 1.3.1.1; SBN 69). As reasoning concerning matters of fact is founded on experience, it is also the source of factual 
knowledge (EHU 4.14; SBN 32). The nature of experience is the following. We remember having observed two species of objects or events as being constantly conjoined in the past (T 1.3.6.2; SBN 87). For instance, I remember that when I placed my finger near to a candle flame, I felt heat. Experience enables me to infer the fact that flame causes heat. Hume contrasts experience to reason, since the latter does not "make us pass from one object to another." This requires the faculty of imagination:

“Reason can never shew us the connexion of one object with another, tho' aided by experience, and the observation of their constant conjunction in all past instances. When the mind, therefore, passes from the idea or impression of one object to the idea or belief of another, it is not determin'd by reason, but by certain principles, which associate together the ideas of these objects, and unite them in the imagination" (T 1.3.6.12; SBN 92; see also Garrett 1997: 76).

Both humans and non-human animals experience. They are both equipped with sensory systems and the faculty of memory. Humans and non-human animals are thus able to perceive objects and events, and infer some constant conjunctions and regularities between them. Both base their causal reasoning — the way in which they identify causality — on the uniformity of nature. "It seems evident," Hume writes "that animals, as well as men learn many things from experience, and infer, that the same events will always follow from the same causes." (EHU 9.2; SBN 105) For example, an experienced horse knows, based on its previous experience, which fences it can jump, so it will not attempt to jump fences that it cannot handle. In chase, an experienced greyhound knows to leave the most fatiguing parts of the chase to the young, unexperienced hounds, instead waiting for the hare in a specific location where it is most likely to appear. 
When animals infer from causes to effects, they do not base their inferences on any principle founded on reason. With an argument from analogy, Hume claims that the same is true with regard to humans:

Animals, therefore, are not guided in these inferences by reasoning: Neither are children: Neither are the generality of mankind, in their ordinary actions and conclusions: Neither are philosophers themselves, who, in all the active parts of life, are, in the main, the same with the vulgar [ordinary people], and are governed by the same maxims (EHU 9.5; SBN 106).

Hume's position on the relation between human and animal cognition is radical. He suggests that reasoning is fundamentally an instinctive process. He maintains that

the experimental reasoning itself, which we possess in common with beasts, and on which the whole conduct of life depends, is nothing but a species of instinct [...] Though the instinct be different, yet still it is an instinct, which teaches a man to avoid the fire; as much as that, which teaches a bird, with such exactness, the art of incubation, and the whole economy and order of its nursery (EHU 9.6; SBN 108).

Hume shrinks the gap between the human and animal reason into a difference of degree. Unlike many of his predecessors, for which Descartes is an excellent example, he did not understand reason as being a quasi-divine feature, a faculty by which humans can 
understands the God-created world. Peter Millican (2007: xlviii-xlix) expounds on the controversiality of Hume's position as compared to many of his predecessors:

Human reason was commonly [in the eighteenth century] thought to be quasidivine or angelic rather than beastlike, a faculty expressing the essence of our unique immaterial soul, capable of providing transparent insight into the nature of things and operating quite independently of brute animal instincts.

In the Treatise Hume strongly criticizes the Cartesian conception by contending that "no truth appears to me more evident, than that beasts are endow'd with thought and reason as well as men" (T 1.3.16.1; SBN 176). He thinks that arguments for this case are "so obvious, that they never escape the most stupid and ignorant" (T 1.3.16.1; SBN 176). In Hume's stance, human reason is not opposite to animal instinct, but emerges from it. Like animals, we humans acquire knowledge of nature by sensory input and frequent experience.

Hume on the relation between human and animal reason and cognition made a deep impact on Darwin. In August 1838, some twenty years before the publication of his Origins of Species, and exactly at the time when Darwin was formulating his theory of natural selection, he was reading the first Enquiry. He wrote in his notebook (N101) that "Hume has section (IX) on Reason of Animals ... he seems to allow it is an instinct." As Hume had claimed, reasoning is a form of natural instinct. By this he means that when humans or non-human animals infer "that like events must follow like objects," they both rely on the assumption "that the course of nature will always be regular in its operations" (EHU 9.5; SBN 106). This assumption of the uniformity of nature is not founded on reasoning in any way. Rather, it is founded on non-voluntary, customary, habitual and instinctive aspects of our natures. 
Darwin wrote in his notebook (after reading Hume) that intellectual activity is a "modification of instinct - an unfolding \& generalizing of the means by which an instinct is transmitted" (Darwin's Notebook N48). As Robert J. Richards (2003: 95) expounds, to Darwin this meant that "human intelligence was, then, not opposed to animal instinct but grew out of it in the course of ages." Darwin's conception draws consciously on Hume as he pointed out that in Hume's account the "origin of reason" is "gradually developed" (Darwin's Notebook N101)

Moreover, Hume's copy principle is also consistent with the position that animal and human mentality are in continuation. As our ideas and thoughts are copied from simple sensory impressions, there is no reason why animals, who possess similar sensory systems than humans, would not be capable of thought. Darwin explored this idea further, and went on to devise a sensationalist epistemology which he wrote down in one of his notebooks. Although Darwin does not explicitly mention Hume in this context, he argued, in a way that would have been very congenial to Hume, that the basis of complex thought is in the comparison of simple sensory images (Darwin's Notebook N21E; Richards 2003: 95).

Darwin's own scientific arguments for the difference of degree between human and animal cognition are made explicit in his main work Of the Origin of Species by Means of Natural Selection from the year 1859. Natural selection results from three combined principles: 1) tendency of offspring to resemble parents, 2) variation, and 3) superfecundity, that is, Malthusian production of more offspring than can possible survive. Thus Darwin puts it as follows: 
As many more individuals of each species are born than can possibly survive; and as, consequently, there is a frequently recurring struggle for existence, it follows that any being, if it vary however slightly in any manner profitable to itself, under the complex and sometimes varying conditions of life, will have a better chance of surviving, and thus be naturally selected. From the strong principle of inheritance, any selected variety will tend to propagate its new and modified form (Darwin 2006: 3).

Because of variation, it is not possible to draw a sharp dividing line between individual differences and slight varieties, between slight varieties and more distinct varieties, between more distinct varieties and sub-species, between sub-species and species, and finally, between species (Darwin 2006: 294). Darwin (2006: 34) stresses that he looks

at the term species as one arbitrarily given for the sake of convenience to a set of individuals closely resembling each other, and that it does not essentially differ from the term variety, which is given to less distinct and more fluctuating forms. The term variety, again, in comparison with mere individual differences, is also applied arbitrarily, and for mere convenience sake.

The conclusion Darwin draws in the Origin is that all forms of life are part of one and the same tree of life. All species have probably evolved from a simple form or few forms of life (2006: 307). 


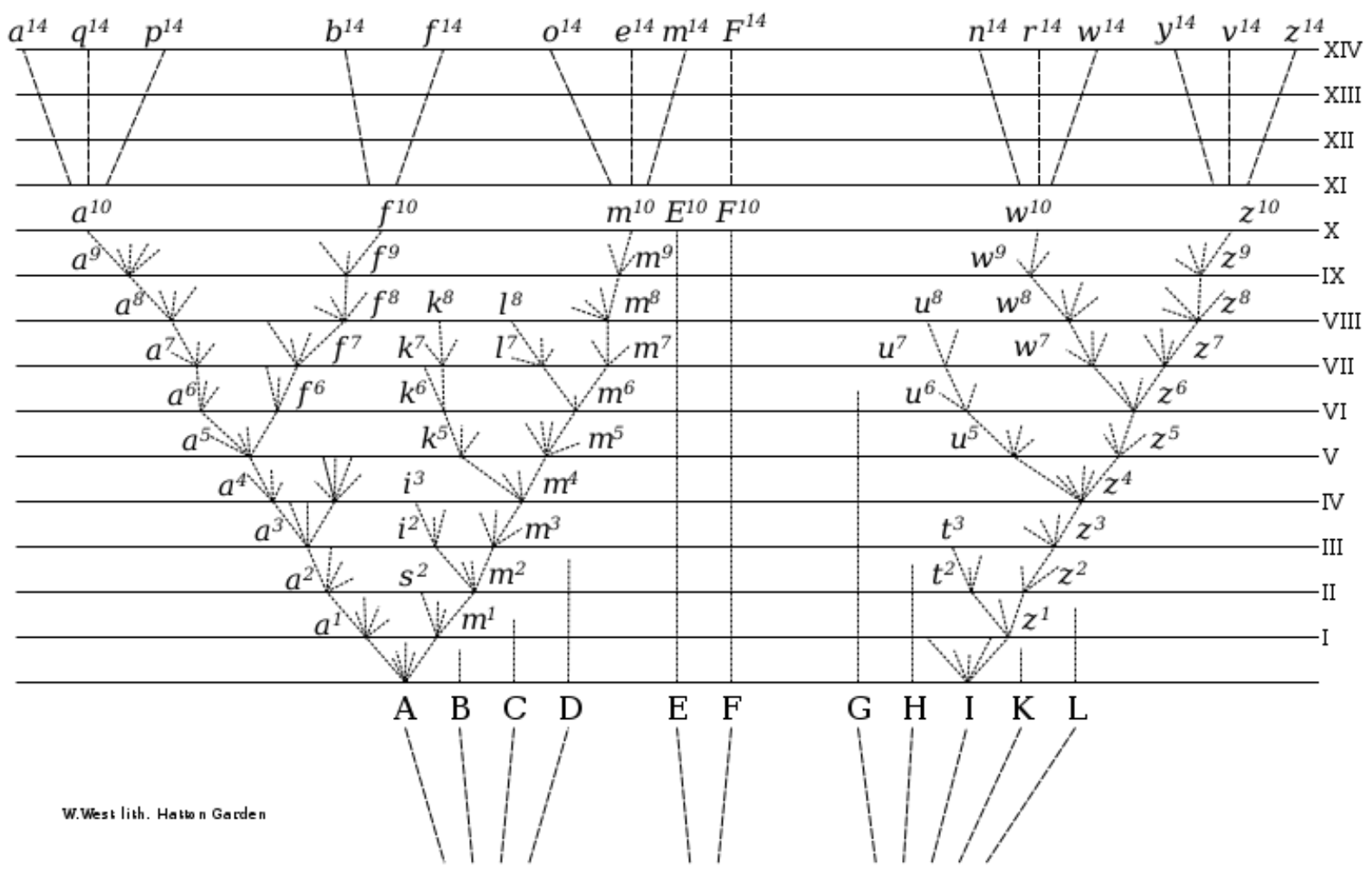

Figure 1 Darwin's tree of life (Diagram of Divergence of Taxa) as depicted in the Origin. Source of the Figure: https://en.wikisource.org/wiki/On_the_Origin_of_Species_(1859)/Chapter_IV.

In his Descent of Man, Darwin does, however, argue that humans have abilities that have developed further than in other animals. Such abilities include the development and application of an articulate language, manufacturing of weapons, tools and traps, abstract thought, and self-consciousness. These capabilities have made human dominance in nature possible. Darwin also thinks that as self-reflecting beings humans are capable of making moral inferences. We can critically review our past actions, and conclude that we could have acted differently (Darwin 2007: 83-4, 404). In this respect, he maintains that there are important differences between humans and other animals. Interestingly, Hume also thinks that non-human animals are not capable of making moral judgments, neither concerning their own actions nor what others should do (Boyle 2003: 21). 
But these differences are nothing like what has been traditionally assumed in the history of Western philosophy. There is no ladder of life_-"nature does not make jumps," as Darwin and many natural philosophers had claimed before him — but a tree of life. And humans are just one branch of this tree.

Hume did not say anything about the common tree of life, or about the way in which the branches of the family tree divide over and over again. It is not clear if Hume even had any position about the nature of species. Accordingly, Hume seems not to have theorized on sexual selection, which is one of the cornerstones of Darwin's work. In the Dialogues, there are some scattered remarks which suggest that Hume had some idea of evolution by means of natural selection. In the line of Philo, Hume writes the following: "You ascribe, Cleanthes, (and I believe justly) a purpose and intention to Nature. But what, I beseech you, is the object of that curious artifice and machinery, which she has displayed in all animals? The preservation alone of individuals and propagation of the species" (DNR 10.26; KS 198, my emphasis). Here Hume says that the purpose of living beings is to survive and produce offspring. This would be consistent with Darwinian evolution by means of natural selection. ${ }^{4}$ Hume also did think, along the same lines with Darwin, that human mental faculties have gradually developed. They are not categorically different from those of the animals. In this respect, Hume's philosophy of animals instantiates a distinctly modern conception. It indicates that it is hopeless to draw a dichotomous and all-encompassing difference between humans and animals. In conclusion: The naturalistic worldview that is apparent in Hume's philosophy was clearly part of the intellectual background of Darwin's scientific work. 


\section{Hume and Einstein: empiricism and relativity of simultaneity}

The commonsensical picture of time is that it flows like a river. We feel that time passes from past to future, no matter what. This picture is also apparent in Newton's major work Principia: The Mathematical Principles of Natural Philosophy, a work that laid the foundation for classical dynamic physics. ${ }^{5}$ Thus Newton writes:

\footnotetext{
Absolute, true, and mathematical time, in and of itself and of its own nature, without reference to anything external, flows uniformly, and by another name it is called duration (Newton 1999: 408).
}

Newton's conception of time as flowing evenly and his understanding that duration is absolute, has two consequences: all observers agree on the absolute simultaneity of events, since the duration between these events is zero, and the durations between all nonsimultaneous events are absolute (Earman 1989: 8). The absoluteness of time signifies that it exists entirely independent of observers, physical objects, or any kind of natural events, such as motion of objects. We can accelerate objects but we cannot have any influence on the flow of time. In Newton's account, observers' relations to objects are insignificant for the structure and passage of time. Time is universal and independent of any specific location:

The moment of duration is the same at Rome and at London, on the Earth and on the stars, and throughout all the heavens $[\ldots]$ each and every indivisible moment of duration is everywhere (Newton 2004: 26; Newton 1999: 941). 
From its inception, Newton's argument for absolute time (and space) has been taken with a grain of salt. To name some figures, important 17th and 18th century philosophers and natural philosophers such as Huygens, G. W. F. Leibniz (1646-1716), and George Berkeley (1685-1753), did not subscribe to Newton's absolutism. There are many reasons for their critical receptions, as well as there are many intricate issues in the philosophy and physics of time. In what follows, I shall zero in on Hume's influence on Einstein. I shall focus on the empiricist epistemology of concepts, and its relation to Einstein's argument for the relativity of simultaneity, which effectively gave Einstein the means to reject Newton's absolute conception of time.

In 1905, Einstein published his article "On the Electrodynamics of Moving Bodies" ("Zur Elektrodynamik bewegter Körper") in the physics journal Annalen der Physik. This is the original publication of the special theory of relativity, although Einstein was not the only scientist who took part in its creation. ${ }^{6}$ The theory originated from a critical reflection of the 19th century electrodynamic physics (see Norton 2014), but it is most well known for putting forth a novel theory of space, and, perhaps more importantly, time. The processes that gave birth to the theory have also philosophical dimensions.

Einstein himself acknowledged the importance of his reading of Hume and Ernst Mach (1838-1916) several times. On December 1915, some ten years after the original publication of special relativity, and around at the time of a series of publications where he devised the general theory of relativity, Einstein was engaged in a correspondence with Schlick. In this correspondence, they discussed the philosophical issues related to special relativity. In one of his letters, Einstein (1998: 220) wrote that Schlick had been correct in recognizing that it was 
Mach, and, even more, Hume, whose Treatise of Human Nature I studied with passion and admiration shortly before discovering the [special] theory of relativity. Very possibly, I wouldn't have come to the solution without those philosophical studies.

Einstein had been reading the German translation of the Treatise in a reading group that he formed with his friends, philosophy student Maurice Solovine (1875-1958), and mathematician Conrad Habicht (1876-1958) around 1902-1903 in Bern (Howard 2005: 36; Janssen, Lehner 2014: 2). In his letter to Schlick, he noted that Hume's role was more important in the formulation of STR than Mach's. Later in 1948, he reiterated his opinion in his correspondence with his friend, engineer Michele Besso (1873-1955):

How far (Mach's writings) influenced my own work is, to be honest, not clear to me. In so far as I can be aware, the immediate influence of D. Hume on me was great. I read him with Konrad Habicht and Solovine in Bern" (Speziali 1972: 153).

In the letters above, Einstein's debts to Hume are vague and unspecific. But there is one piece of textual evidence in his 1949 autobiographical notes where he is more specific. He points out that while forming the theory of special relativity, it was necessary to reject the false "axiom of absolute character of time, viz., simultaneity." This axiom, he writes,

unrecognizedly was anchored in the unconscious. Clearly to recognize this axiom and its arbitrary character really implies already the solution of the 
problem. The type of critical reasoning required for the discovery of this central point [the denial of absolute time, that is, the denial of absolute simultaneity] was decisively furthered, in my case, especially by the reading of David Hume's and Ernst Mach's philosophical writings (Einstein 1949: 53).

In general, historians and philosophers of physics have taken Hume's influence (or the influence coming from the empiricist and the positivist tradition more broadly) on Einstein to have focused on this central point (Norton 2010: 360, footnote 2). Understanding the relativity of simultaneity was a key to reconcile the two seemingly contradictory postulates of the theory: the light principle, and the invariance principle. According to the first principle, the velocity of light in a vacuum, $c$, is constant. It is independent of the motion of the emitting source of the light. According to the latter, laws of physics are invariant in all inertial frames of reference. They apply in the same way for all uniformly moving or stationary observers (measuring devices).

As noted before, our commonsensical Newtonian picture of time tells us that time flows like a river. From the viewpoint of empiricist philosophy, the problem is that time in itself-if there were such a thing - is not something one can perceive. We do not acquire information of the putative flow of absolute time by our senses; time itself cannot be seen, touched, heard, tasted or smelt.

If one is an empiricist about the idea or the concept of time, then its idea or concept has to be somehow related to a perception, observation, or experience. As John D. Norton (2010) shows, it was an empiricist account of concepts that Einstein learned from his reading of Hume (as well as Mach and possibly the empiricist and the positivist tradition of philosophy 
in general). Einstein's insight was to implement this empiricism into his argument for the relativity of simultaneity. In his popular book Relativity. The Special and General Theory from the year 1916, Einstein presents his argument with the following thought experiment.

Imagine two inertial frames of reference. These are two rigid bodies, a train and a railway embankment.

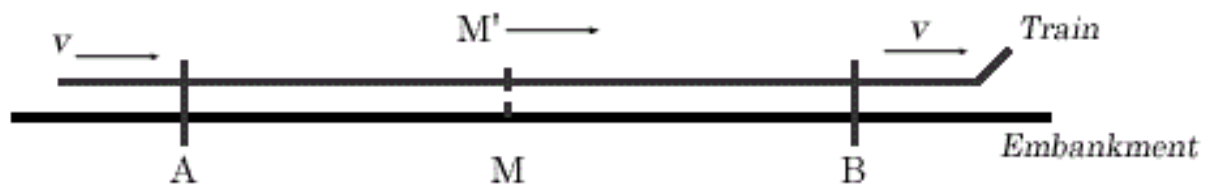

Figure 2: The relativity of simultaneity in Einstein's (2001: 27) example. Source of the Figure: https://en.wikisource.org/wiki/Relativity:_The_Special_and_General_Theory/Part_I

There are two observers, $\mathrm{M}$ and $\mathrm{M}^{\prime}$, and two places at the embankment, $\mathrm{A}$ and $\mathrm{B}$. The observer $\mathrm{M}$ is at rest with respect to the embankment, while the observer $\mathrm{M}^{\prime}$ is at rest with respect to the train. $\mathrm{M}$ sees the train passing her by with a constant velocity $v$. While $\mathbf{M}^{\prime}$ passes M, they are both located at the mid-point of the line AB.

When the train passes $\mathrm{M}$, two lightings strike to points A and $\mathrm{B}$. The observers are both equipped with two mirrors that are inclined at 90 degrees. These mirrors enable them to see the receiving light coming from points $\mathrm{A}$ and $\mathrm{B}$. The light travels with constant velocity $c$ (all observers agree on the speed of light (in a vacuum), as established by the theory's light principle). 
The observer M sees the lightning strikes to happen simultaneously. But how does the observer M' see the time ordering of the strikes? She is moving toward point B, and away from the point A. Therefore she is also hastening toward the light beam coming from point B, and away from the light beam coming from point A. In her inertial frame of reference, the lightning striking point B occurs before the lighting strike at point A. Consequently for her the strikes are non-simultaneous, that is, successive. "We thus arrive," Einstein (2001: 28-9) explains

at the important result: Events which are simultaneous with reference to the embankment are not simultaneous with respect to the train, and vice versa (relativity of simultaneity). Every reference-body (co-ordinate system) has its own particular time; unless we are told the reference body to which the statement of time refers, there is no meaning in a statement of the time of an event.

Crucial to Einstein's $(2001: 25,29)$ argumentation is the definition of the concept of simultaneity in empirical terms. Without the observation of lightning strikes in the experiment, one would not be "able to attach a meaning to the statement of simultaneity." The essential demand to this concept is "that in every real case it must supply us with an empirical decision as to whether or not the conception that has to be defined is fulfilled." Once simultaneity is so defined, the Newtonian absolutist assumption can be discarded, and the apparent tension between the two postulates of the theory of special relativity disappears. Einstein comments on the historical significance of the discovery of this central point: 
Now before the advent of the theory of relativity it had always tacitly been assumed in physics that the statement of time had an absolute significance, i.e. that it is independent of the state of motion of the body of reference.

With the aid of empiricist philosophy, Einstein rendered the concept of time an empirical one. It can be decided by experimental means that simultaneity and duration between two noncausally related physical events is relative to inertial frames of reference. Judgments about time are judgments about simultaneous events in which any freely chosen periodically recurring system, such as a clock, is compared to a reference-object, that is, to an inertial frame of reference. Time-interval between two ticks of a clock is shortest in the frame of reference where the clock is at rest (Knight 2008: 1158); there is no meaning in speaking of any "absolute," or "true" time to which any specific clock could be compared to. In special relativity (a theory which has now been extremely well confirmed), there is no absolute flow of time from earlier to later, from past to future. ${ }^{7}$ Time is not absolute nor universal the way Newton thought it would be.

Hume and the empiricist tradition did not only shape Einstein's views on the epistemology of concepts. I have argued (Slavov 2016) that there are also analogies between Hume's and Einstein's ontological positions concerning space and time. They are both relationists. An important aspect of both Hume's and Einstein's ontologies is this: they relate the idea or the concept of time to objects. 
In Hume the abstract idea of time is acquired by perceiving change. It "can never be convey'd to the mind by any thing stedfast and unchangeable," he writes (T 1.2.3.11; SBN 37). This change is perceivable either through succession or relative motion of objects. By hearing five successive flute chords, we can abstract the idea of time from the succession of the chords. Time is not something that is caused by an individual chord, a simple auditory impression. No single ongoing chord could cause the idea of time to the mind, because there is nothing changing in this object. Rather, we need to perceive a sequence of chords and pauses to get time's idea. Another way for us to acquire the idea of time is to perceive relative change of motion of bodies. Motion gives us the idea of time as "every moment is distinguish'd by a different position" of the moving object (T 1.2.5.29; SBN 65; Baxter 2008: 30). Hume encapsulates his argument concerning the origin of the idea of time:

Wherever we have no successive perceptions, we have no notion of time, even tho' there be a real succession in the objects. From these phaenomena, as well as from many others, we may conclude, that time cannot make its appearance to the mind, either alone, or attended with a steady unchangeable object, but is always discover'd by some perceivable succession of changeable objects ( $\mathrm{T}$ 1.2.3.7; SBN 35).

Time consists of indivisible moments that are parts of succession. For us to acquire the idea of time, it is requisite that these parts appear to be changing:

Now as time is compos'd of parts, that are not co-existent; an unchangeable object, since it produces none but co-existent impressions, produces none that can give us the idea of time; and consequently that idea must be deriv'd from a 
succession of changeable objects, and time in its first appearance can never be sever'd from such a succession (T 1.2.3.8; SBN 36).

To understand Hume's reasoning, ${ }^{8}$ imagine a stationary observer in front of a huge grey wall. The wall is evenly painted, and it covers the observer's whole visual field. In this scenario, there is nothing changing in front of her. The wall is a steadfast object. It has no duration. Such unchangeable object cannot be the source for the idea of time, alone.

Now, if something changing, like a blue object moving in front of the wall, appears, the observer will be able to acquire the idea of time through change of place of the object. Although the wall is a steadfast object, the "co-existing" moving item is not. It is changing its location as it is moving. Its moments, that is, different spatial locations with respect to the wall, are distinguishable. So there is apparent succession. However, this change or the appearance of succession is related to the observers' viewpoint. If the observer would be moving together with the object at the same relative velocity, there would not be any apparent change in her viewpoint. ${ }^{9}$

Hume's conception of time is clearly non-absolutist. There is no one universal time but different times. The way we perceive time depends on observer's relations to objects. There is no absolute time (or we do not have its putative idea) independent of this relation. It is not "possible for time alone ever to make its appearance," as "time is nothing but the manner, in which some real objects exist," Hume says (T 1.2.3.7; SBN 35, 1.2.5.28; SBN 64; see also Isaacson 2008: 82). 
Hume is conscious that his account of time is against the "common opinion of philosophers as well as of the vulgar," who assume that steadfast objects endure. Because of his strict empiricism, Hume cannot accept such a false notion. It is by means of "fiction," that is, without having ideas that "represent the objects or impressions, from which they are deriv'd" that "we apply the idea of time, even to what is unchangeable" (T 1.2.3.11; SBN 37). "There is no observable evidence that the structure of time is uniform across space," notes Baxter (2015: 214).

As in Hume, Einstein's ontology of time is also intrinsically related to his empiricism.

Consider the following arguments of Einstein:

"in any ontological question, our concern can only be to seek out those characteristics in the complex of sense experiences to which the concepts refer" (1981: 271).

"[concepts] of space and time can only claim validity in so far as they stand in a clear relation to experiences" (Norton 2010: 369).

Although there are essential similarities between Hume and Einstein's philosophical analysis related to his special relativity, namely the intertwinement of empiricism of concepts and relationist ontology concerning space and time, there are also crucial differences. These differences pertain both to the epistemology of ideas and concepts as well as to the ontology of time (and space). 
Hume's empiricism is much more radical than Einstein's. In Hume simple ideas are caused by simple impressions; the origin of all of our simple ideas are in sensuous impressions. Einstein does not share this view. In his account, "physical concepts are free creations of the human mind" (Einstein, Infeld 1960: 31). He thought that the formation of concepts requires conventional stipulations. He did not subscribe to Hume's position concerning the origin of concepts (abstract ideas). On the other hand, both Hume and Einstein seem to have thought that the way ideas or concepts get their meaning and justification is by a reference to sensuous impressions.

Regarding the ontology of time, Hume is concerned with the way the mind acquires the idea of time. In Einstein's account, time is a physical quantity. This indicates that when the two are speaking about time, they are not referring to the exact same thing. Hume is more interested in the psychological and phenomenological dimensions of time, the way the human mind perceives time. Einstein is addressing physical time, that is, time as a natural phenomenon. To Einstein "observer" is a technical term which denotes an inertial frame of reference with respect to with a measurement device is at rest. As Bradley Dowden comments, the observer "need not to have a mind." (Dowden 2017)

Moreover, according to Hume's view, the ideas of space and time are distinctly separable; there are successions of impressions (such as auditory impressions) which are not themselves physically located (T 1.4.5.10; SBN 235; Baxter 2008: 37). This means that in Hume there can be time without physical events taking place. To the contrary, Einstein's argument for the relativity of simultaneity connects temporal order to the order in which physical events take place (in a specific inertial frame). The order of events can be different from experimenters' 
direct observations of the timely order of events. To quote from a contemporary physics textbook (Knight 2008: 1153), the crux of the matter is this:

Simultaneity is determined by when the events actually happen, not when they are seen or observed. In general, simultaneous events are not seen at the same time because of the difference in light travel times from the events to an experimenter.

In special relativity it is a mistake to conflate "'simultaneously seen' and 'simultaneously happening,'" as Einstein (1936: 358) himself asserts. It is not clear whether Hume's radical (and skeptical) empiricism could license us to infer that our perceptions are different from physical events, and that our perceptions are caused by perception-independent natural events.

However, in both Hume and Einstein their epistemology of ideas and concepts is related to their ontological commitments concerning time, so it is meaningful to compare their views. As there are salient confluences of their positions, and as there is evidence that Einstein was reading Hume before the formulation of his new theory, it can be concluded that Hume's philosophy did partly contribute to Einstein's work with his special relativity. 


\section{References:}

Ayer, A. J. (1959) "Introduction," in Ayer, A.J. (ed.) Logical Positivism, London: The Free Press.

— (1987) "Reflections on Language, Truth, and Logic," in Gower, B. (ed.) Logical

Positivism in Perspective: Essays on Language, Truth and Logic, London and Sydney:

Croom Helm.

— (2001) Language, Truth and Logic, London: Penguin.

Baxter, D. L. M. (2008) Hume's Difficulty. Time and Identity in the Treatise, London and New York: Routledge.

— (2015) "Descartes and Hume on Duration," Proceedings of The 42nd International Hume Society Conference Stockholm: 203-16.

Beebee, H. (2006) Hume on Causation, New York: Routledge.

Blackburn, S. (2009) “Is human nature natural?” In Hodge, J., Radick, G. (eds.) The Cambridge Companion to Darwin, Second Edition, New York: Cambridge University Press.

Boyle, D. (2003) "Hume on Animal Reason," Hume Studies 29 (1): 3-28. 
Bunnin, N., Yu, J. (2004) The Blackwell Dictionary of Western Philosophy, Malden, Oxford, Victoria: Blackwell Publishing.

Carroll, J. W. (2016) "Laws of Nature", The Stanford Encyclopedia of Philosophy (Spring 2016 Edition), Edward N. Zalta (ed.), URL = <http://plato.stanford.edu/archives/spr2016/entries/laws-of-nature/>.

Cartwright, N. (1979) “Causal Laws and Effective Strategies,” Noûs 13: 419-37.

Chambers, E. (1728) Cyclopadia, or an Universal Dictionary of Arts and Sciences, 2 volumes, with the 1753 supplement. Digitized by the University of Wisconsin Digital Collections Center, http://digital.library.wisc.edu/1711.dl/HistSciTech.Cyclopaedia.

Clark, M. T. (2000) An Aquinas Reader, New York: Fordham University Press.

Damasio, A. (1995) Descartes' Error: Emotion, Reason, and the Human Brain. New York: Avon Books.

Darwin, C. (2006) On the Origins of Species by Means of Natural Selection, Mineola, New York: Dover.

— (2007) The Descent of Man, and Selection in Relation to Sex, New York: Penguin.

Descartes, R. (2000) Discours de la méthode, D. Moreau (ed.), Paris: Librairie Générale Française. 
DiSalle, R. (2002) "Newton's Philosophical Analysis of Space and time," in Cohen, I. B., Smith, E. (eds.) The Cambridge Companion to Newton, New York: Cambridge University Press.

Dowden, B. (2017) "Time," The Internet Encyclopedia of Philosophy, ISSN 2161-0002, http://www.iep.utm.edu/time/.

Earman, J. (1989) World Enough and Space-Time: Absolute versus Relational Theories of Space and Time, Cambridge, MA, London, England: The MIT Press.

Einstein, A. (1905) "Zur Elektrodynamik bewegter Körper," Annalen der Physik 332 (10): 891-921.

— (1936) Physics and Reality, J. Piccard (trans.), Journal of the Franklin Institute 221 (3): $349-82$.

— (1949) "Autobiographical Notes," in Schilpp, P. A. (ed.) Albert Einstein: PhilosopherScientist, Volume VII in the Library of Living Philosophers, New York: MJF Books.

— Infeld, L. (1960) The Evolution of Physics, from Early Concepts to Relativity and Quanta, New York: Simon Schuster.

— (1981) “The Problem of Space, Ether, and the Field in Physics," in Seelig, C. (ed.) Ideas and Opinions, Sonja Bargmann (trans.), New York: Dell Publishing. 
— (1998) The Collected Papers of Albert Einstein. Volume 8: The Berlin Years:

Correspondence, 1914-1918, (eds.) Schulmann, R., Kox, A. J., Janssen, M., Illy, József, Princeton: Princeton University Press.

- (2001) Relativity. The Special and General Theory, R. W. Lawson (trans.), London and New York: Routledge.

Garrett, D. (1997) Cognition and Commitment in Hume's Philosophy, New York: Oxford University Press.

Godfrey-Smith, P. (2003) Theory and Reality: An Introduction to the Philosophy of Science, Chicago and London: The University of Chicago Press.

Harris, J. A. (2015) Hume: An Intellectual Biography, New York: Cambridge University Press.

Howard, D. (2005) "Albert Einstein as a Philosopher of Science," Physics Today, December 2005, http://dx.doi.org/10.1063/1.2169442.

Hume, D. (1998) Dialogues concerning Natural Religion, R. H. Popkin (ed.), Indianapolis, Cambridge: Hacket Publishing.

— (2000) An Enquiry concerning Human Understanding, T. L. Beauchamp (ed.), Oxford: Clarendon Press. 
— (2007) A Treatise of Human Nature, D. F. Norton, M. J. Norton (eds.), Oxford: Clarendon Press.

Isaacson, W. (2008). Einstein: His Life and Universe, New York: Simon \& Schuster Paperbacks.

Janssen, M., Lehner, C. (2014) "Introduction" in Janssen, M., Lehner, C. (eds.) The

Cambridge Companion to Einstein, New York: Cambridge University Press.

Knight, R. D. (2008) Physics. For Scientists and Engineers. Second Edition, San Francisco: Pearson Addison-Wesley.

Ladyman, J., Ross, D. (2007) Every Thing Must Go: Metaphysics Naturalized, New York: Oxford University Press.

Lovejoy, A. O. (1936) The Great Chain of Being: A Study of the History of an Idea, Cambridge: Harvard University Press.

Meeker, K. (2011) "Quine and Hume and the Analytic/Synthetic Distinction," Philosophia 39 (2): 369-73.

Menzies, P. (2014) "Counterfactual Theories of Causation", The Stanford Encyclopedia of Philosophy (Spring 2014 Edition), Edward N. Zalta (ed.), URL= <http://plato.stanford.edu/archives/spr2014/entries/causation-counterfactual/>. 
Mill, J. S. (1963) System of Logic, Ratiocinative and Inductive, in Robson, J. M. (ed.)

Collected Works of John Stuart Mill, volumes 7 and 8, Toronto: University of Toronto Press.

Millican, P. (2007) "Introduction” to Enquiry concerning Human Understanding by David Hume, New York: Oxford University Press.

Morris, W. E. (2011) “Hume’s Epistemological Legacy,” in Radcliffe, E. S. (ed.) A Companion to Hume, Malden, Oxford, West Sussex: Wiley-Blackwell.

Newton, I. (1999) The Principia: Mathematical Principles of Natural Philosophy, Cohen, I.

B., Whitman, A. (eds., trans.), Budenz, J. (assist.), Berkeley, Los Angeles, London: University of California Press.

Newton, I. (2004) "De Gravitatione," in Janiak, A. (ed.) Isaac Newton. Philosophical Writings, New York: Cambridge University Press.

Norton, J. D. (2010) "How Hume and Mach Helped Einstein Discover Special Relativity," in Dickson, M., Domski, M. (eds.) Discourse on a New Method: Reinvigorating the Marriage of History and Philosophy of Science, Chicago and La Salle, Illinois: Open Court.

— (2014) "Einstein's Special Theory of Relativity and the Problems in the Electrodynamics of Moving Bodies That Lead Him to It," in Janssen, M., Lehner, C. (eds.) The Cambridge Companion to Einstein, New York: Cambridge University Press. 
Ott, W. (2009) Causation and Laws of Nature in Early Modern Philosophy, New York: Oxford University Press.

Passmore, J. (1967) “Logical Positivism,” in Edwards, P. (ed.) The Encyclopedia of Philosophy, Volume 5, New York: Macmillan.

Popper, K. (1972) Objective Knowledge: An Evolutionary Approach, New York: Oxford University Press.

Quine, W. V. O (1951) “Two Dogmas of Empiricism,” The Philosophical Review 60 (1): 2043.

Richards, R. J. (2003) "Darwin on mind, morals and emotions," in Hodge, J., Radick, G. (eds.) The Cambridge Companion to Darwin, New York: Cambridge University Press.

Rosenberg, A. (1993) "Hume and the Philosophy of Science," in Norton, D. F. (ed.) The Cambridge Companion to Hume, New York: Cambridge University Press.

Slavov, M. (2016) “Empiricism and Relationism Intertwined: Hume and Einstein’s Special Theory of Relativity," Theoria: An International Journal for Theory, History and Foundations of Science 31 (2): 247-63.

Speziali, P. (1972) Albert Einstein, Michelle Besso. Correspondence 1903-1955, Paris: Hermann. 
Wilson, F. (2016) “John Stuart Mill,” The Stanford Encyclopedia of Philosophy (Spring 2016 Edition), Edward N. Zalta (ed.), URL = <http://plato.stanford.edu/archives/spr2016/entries/mill/>.

Wittgenstein, L. (2009) Philosophical Investigations, Anscombe, G. E. M, Hacker, P. M. S., Schulte, J. (eds. trans.), Fourth Edition, Malden, Oxford, West Sussex: Wiley-Blackwell. Woodward, J. (2003) Making Things Happen: A Theory of Causal Explanation, New York: Oxford University Press.

van Wyhe, John. (2002) "Darwin's Notebooks and Reading Lists," in The Complete Work of Charles Darwin Online, http://darwinonline.org.uk/EditorialIntroductions/vanWyhe_notebooks.html.

Zirkle, C. (1941) "Natural Selection before the 'Origin of Species,'" Proceedings of the American Philosophical Society 84 (1): 71-123.

\section{Notes:}

\footnotetext{
${ }^{1}$ It is somewhat problematic to depict "natural philosophy" in the 17 th and 18 th centuries as "natural science." The disciplinary boundaries of our time are not the same as they were in the early modern world. Moreover, potential terminological confusions may arise when we use our contemporary language to interpret the past. The meaning of the word "philosophy" in the 18th century context is quite close to the meaning of the word "science" in our
} 
contemporary use of the term. See the entry of "Philosophy" in Ephraim Chambers' dictionary from the year 1728 (Chambers 1728: 803).

${ }^{2}$ Kevin Meeker (2011) has challenged Ayer's interpretation.

${ }^{3}$ For different interpretations on Hume on causation, see Helen Beebee (2006: Chapters 5, 6 and 7).

${ }^{4}$ For history of natural selection before Darwin, see Conway Zirkle (1941). On Hume's relation to Darwinism, see Simon Blackburn (2009).

${ }^{5}$ To just say that our commonsensical picture of time is similar compared to Newton's conception of time is certainly an understatement. In short, the aim of Newton's argument for absolute space and time in the Scholium to the Definitions of the Principia is to make a difference between true and relative motion, that is, between acceleration exerted by a force and rest or motion with constant velocity. However, in this chapter, it is not possible to properly analyze Newton's account. For a thorough analysis of Newton's argument for absolute space and time, see Robert DiSalle (2002).

${ }^{6}$ Although Einstein is credited for the first publication of STR, many mathematicians and physicists took part in its creation, including Hendrik Lorentz (1853-1928), Henri Poincaré (1854-1912), and Hermann Minkowski (1864-1909) (Janssen, Lehner 2014: 11). 
${ }^{7}$ However, there are other physical theories which indicate the direction of time, such as the second law of thermodynamics.

${ }^{8}$ Donald L. M. Baxter (2009: 37) provides a "brick wall" diagram that is very helpful for understanding Hume's reasoning in this issue.

${ }^{9}$ In this idealized example, observers' bodily motions are not taken into account. She could also have a succession of ideas in the mind, which would be a source for the idea of time. 